\title{
Peer review art
}

\author{
Shahryar Sorooshian \\ Faculty of Industrial Management, and Centre for Earth Resources Research \& Management, University of Malaysia Pahang, \\ Malaysia
}

\section{Dear Editor:}

This letter tries to enhance the presented information in the Unworthy peer review process and publishing method, ${ }^{1}$ which has been recently published by this journal. In a peer review journal, subsequent to submission of a manuscript for possible publication, it undergoes a desk-check by the main editor or his/her assistants. Journal team has to decide, either to accept submission and start the peer review process or deny the submission. If the submitted manuscript does not match the necessary standards of the journal, editors usually decide to deny the submission and send the submission back to the author(s). Usually, the necessary standards of the journals to be checked are the writing quality, scope of the work/research and manuscript preparations and formatting. However, since many of the rejections are due to submissions, which are out of the journals' scope, journals may try to save the author's time if the journals check the scope of the papers before comments on the format. There are many cases of rejection due to the formatting problem, and when the author spends more time on the format

Correspondence: Shahryar Sorooshian, Faculty of Industrial Management, and Centre for Earth Resources Research \& Management, University of Malaysia Pahang, Malaysia. E-mail: sorooshian@gmail.com

Key words: Peer review process; journal management; publication.

Acknowledgments: the author would like to thank research grants provided by UMP, RDU140107 and RDU170335.

Conflict of interest: the author declares no potential conflict of interest.

Received for publication: 27 June 2017.

Accepted for publication: 30 June 2017.

This work is licensed under a Creative Commons Attribution NonCommercial 4.0 License (CC BY-NC 4.0).

CCopyright S. Sorooshian, 2017

Licensee PAGEPress, Italy

Italian Journal of Medicine 2017; 11:424-425

doi:10.4081/itjm.2017.897 corrections, the next submission rejection from the same journal refers to the scope of the work, which does not match with the journal. Moreover, the editor needs to assure that the work appears technically reliable and valid. Next, after the document file is checked for the basic standards, the editor needs to send the paper for peer review.

A professional Editor-in-Chief could enhance the quality and branding of the journal, professional networking, and will bring more contributors and authors who wish to publish with the journal. Preference of journals is in nominating a well-known professor as their Editor-in-Chief. However, many professors are too busy to collaborate with the journal. The current problem with some journals is their non-active Editor-in-Chief. In those journals, the Editor-in-Chief is a post with not much responsibility. The main role will be played by associate editors or in some cases, journal secretaries.

Also for a professional journal, a good thing to do is inviting a professional reviewer. However, many professor-scholars are occupied with multi-tasks (such as teaching, research, postgraduate supervision, etc.) and sometimes they are not able to finish the review task in a specified short period of time. A fast review process and the time represent a concern for authors as well as for editors. Therefore, the other problem in the current practiced peer-review system, is given by some less professional journals which prefer to work with reviewers who are not very expert in the field but have more free time to spend in the review of articles.

After the reviewers submit their review reports, the editor evaluates the reports to make sure that the reviewer's judgments and comments are reasonable. Unfortunately, some journals avoid the post-check of the review comments. These journals will send the reviewer comment to the author with no accuracy and validity check. Remarkably in multidisciplinary journals encompassing a wide range of subject areas, many of the reviewers' comments will be evaluated by the editor's expertise.

In many cases, there are corrections or improvements, which the reviewer believes would be required to fit the paper for publication. Progressively, following the comments receival, the authors improve their 
work and resend it for the likely publication. The editors need to understand if the author(s) does not fully agree with the review report. For some comments the author should be able to decide not to accept the recommended changes, then it is crucial for him/her to offer a comprehensive explanation for editor's decision making. The editor(s), author(s), and reviewer(s) should believe that they are all involved in a quality process of peer-review. Thus, when all parties professionally play their role, the scientific society benefits from a good job.

\section{Reference}

1. Dadkhah M, Bianciardi G. Unworthy peer review process and publishing method. Ital J Med 2017;11:82-3. 